Copyright (C 2014 IEEE. Personal use of this material is permitted. Permission from IEEE must be obtained for all other uses, in any current or future media, including reprinting/republishing this material for advertising or promotional purposes, creating new collective works, for resale or redistribution to servers or lists, or reuse of any copyrighted component of this work in other works. 


\section{A Novel Model of Internal Combustion Engine for High Efficiency Operation of Hybrid Electric Vehicles and Power Systems}

\author{
Shane Overington, Member, IEEE \\ Department of Electrical and Computer Engineering \\ Curtin University \\ Perth, Western Australia
}

\author{
Sumedha Rajakaruna, Senior Member, IEEE \\ Department of Electrical and Computer Engineering \\ Curtin University \\ Perth, Western Australia
}

\begin{abstract}
This article realizes a novel model of an internal combustion engine (ICE) based on its operating torque and speed for the purpose of designing new control strategies to optimize engine efficiency and performance in hybrid electric vehicles and power systems. The proposed model is developed such that it utilizes only a limited number of experimentally measured operating conditions of the internal combustion engine. Therefore it helps in minimizing the expensive and time consuming testing of the vehicle under a large number of operating conditions in comparison to other models. On the other hand, it is possible to utilise the model to determine a novel control strategy for fuel consumption reduction in plug-in hybrid electric vehicles (PHEV) and hybrid electric vehicles (HEV). This fuel consumption reduction is achieved through the use of the proposed model to predict the efficiency of operation of the ICE instead of the fuel utilization predicted by conventional models. In order to prove the accuracy of the proposed model, efficiency of operation of six known ICEs have been modelled and compared with three existing models utilizing larger numbers of experimental data. The errors in efficiency in comparison to known data are found to be within a reasonable range. The paper finally demonstrates the possible applications of the proposed model in high efficiency control of ICE in a model of the 2010 Toyota Prius developed using experimental data. The demonstration for the proposed model is in the form of a vehicular system however it is envisaged that this model has applications in hybrid power systems also.
\end{abstract}

Index Terms - Control; Efficiency model; Energy management; Hybrid power source; Hybrid electric vehicle; Internal combustion engine; Speed; Torque

\section{INTRODUCTION}

$\mathrm{T}$ he modelling of ICEs over the past 30 years has led to a significant research base for a number of energy management applications. The ICE has a large number of characteristics and parameters that determine varying operating conditions. These include fuel consumption rate, brake mean effective pressure (bmep), fuel to air $(F / A)$ ratio, temperature, firing angle, displacement, torque-speed characteristics and specific fuel consumption $(s f c)$ to name the most common parameters. The model resulting from the consideration of these parameters is a very complex system that would take significant time to obtain solutions to individual load requirements [1-3]. The minimizing of fossil energy consumption and emissions of harmful gases while maximizing vehicle performance are the key design objectives in most modern day vehicles [4, 5]. This paper therefore proposes a novel control model of the ICE efficiency suitable for optimal efficiency control of hybrid power sources such as those utilised in energy smart vehicles and hybrid power generating systems.

Typically ICE controllers refer to discretely defined performance maps to anticipate the fuel consumed at a

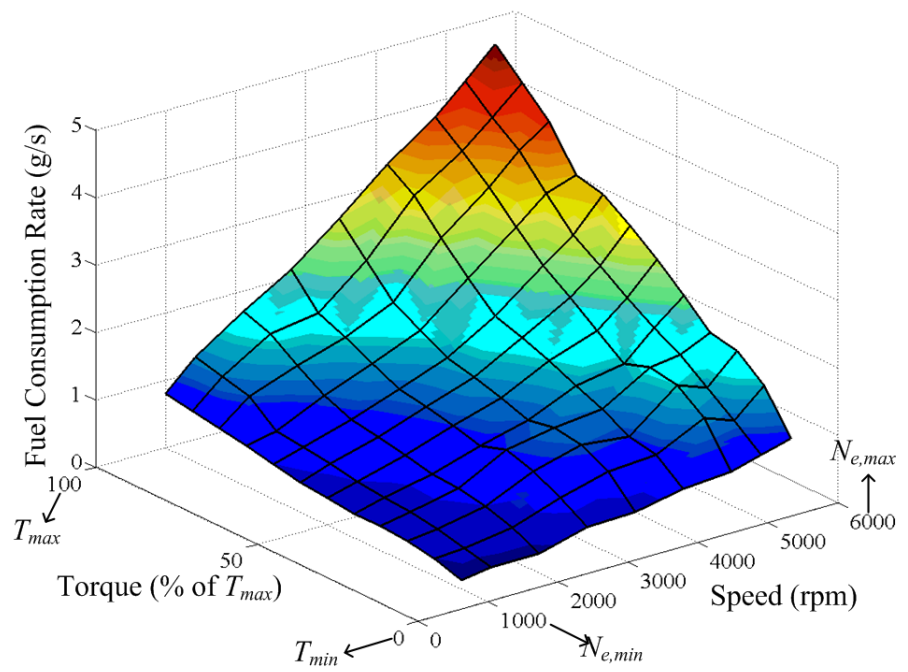

Fig. 1. ICE performance map - showing the fuel consumption with respect to brake torque and speed of the 1.0 L Geo ICE

particular output torque and speed of operation [6]. These performance maps have a limited number of predetermined operating conditions of corresponding fuel consumption, torque and speed. An example of a typical performance map is given in Figure 1. These discretely defined performance maps are determined for sets of ICEs having identical specifications through extensive testing and measuring. This analysis of sets of ICEs identifies a sample space of ICE fuel consumption resulting from specific combinations of output torque and speed. In turn the sample space is refined and utilised to define the expected fuel consumption throughout a range of operating conditions. The operating conditions in the case of the performance maps consist of magnitudes of varying torque and speed. The determined performance map is then utilised for ICE that have the same specifications. During operation a requested torque and speed will result with a fuel consumption similar to that recorded in the performance map [7]. The performance map is then stored in one of two forms for use by a control system for fuel consumption minimisation and emissions reduction.

Performance maps of ICEs are frequently used for real-time fuel consumption minimisation strategies, since approximate fuel consumption is determined instantaneously depending on the ICE operating conditions [8-13]. The most common method for storing the performance map data is in a look-up table, where requested torque at a given vehicle speed can easily be determined. This requires two simple calculations including the expected ICE output torque relative to the 
throttle position of the vehicle and the speed of the ICE relative to the vehicle speed [14]. Using the expected ICE output torque and known operating speed in combination with the look up table the engine control unit (ECU) has a predetermined fuel consumption rate which can be optimised according to some cost function for energy management purposes.

Such models can be easily incorporated in microcontrollers used to control the energy management and power delivery of vehicles. However, when ICE are used in hybrid systems such as off-grid power generating systems, what are most needed in control systems are the efficiencies of individual power sources as opposed to fuel consumption rates. Figure 2 is an example of such a performance map referencing ICE efficiency of operation as opposed to the fuel consumption rate of Figure 1. Such a mathematical model of ICE predicting real-time efficiency at the operating conditions has not been utilised in the manner demonstrated in this paper $[4,8-13,15-$ 20].

Previous work by the authors identifies the advantages of operating ICE of PHEV powertrains within some predefined high efficiency region for ICE operation [21]. The methods for ICE control to achieve the ICE operating restrictions are defined as a power balancing strategy (PBS) combined with variable speed control (VSC). In particular VSC refers to an optimal power-speed line which is similar to the defined optimal operating line (OOL) method featured in [22]. In order to achieve the high efficiency region for ICE operation the controller requires knowledge of the performance map. This paper endeavours to define the potential for high efficiency control without extensive knowledge of the performance map.

This paper is organised as follows; firstly section II outlines the proposed efficiency model. Section III discusses the accuracy of the proposed model and the effect on the fuel consumption of PHEV and HEV. Finally section IV summarises the contributions made in this paper.

\section{Methodology}

\section{A. ICE Torque-Speed Characteristic}

To obtain the operating points of an arbitrary ICE it is possible to approximate the maximum brake torque curve $\left(T_{e, \text { curve }}\right)$ using a parabolic estimation [3]. This maximum brake torque corresponds to the bmep of an ICE which is achieved at wide-open-throttle (WOT). An example of the maximum brake torque is identified as $T_{e, \text { curve }}$ in Figure 3 with;

$$
T_{e, \text { curve }}=a N_{e}^{2}+b N_{e}+d
$$

where coefficients $a, b$, and $d$ can be determined from the ICE specifications. The differential of (1) set equal to zero gives maximum torque (2);

$$
N_{e, T \max }=\frac{-b}{2 a}
$$

Direct substitution of the known rated ICE torque-speed point $\left(N_{e, T \max }, T_{e, \max }\right)$ into (1) yields;

$$
T_{e, \max }=a N_{e, T \max }^{2}+b N_{e T \max }+d
$$

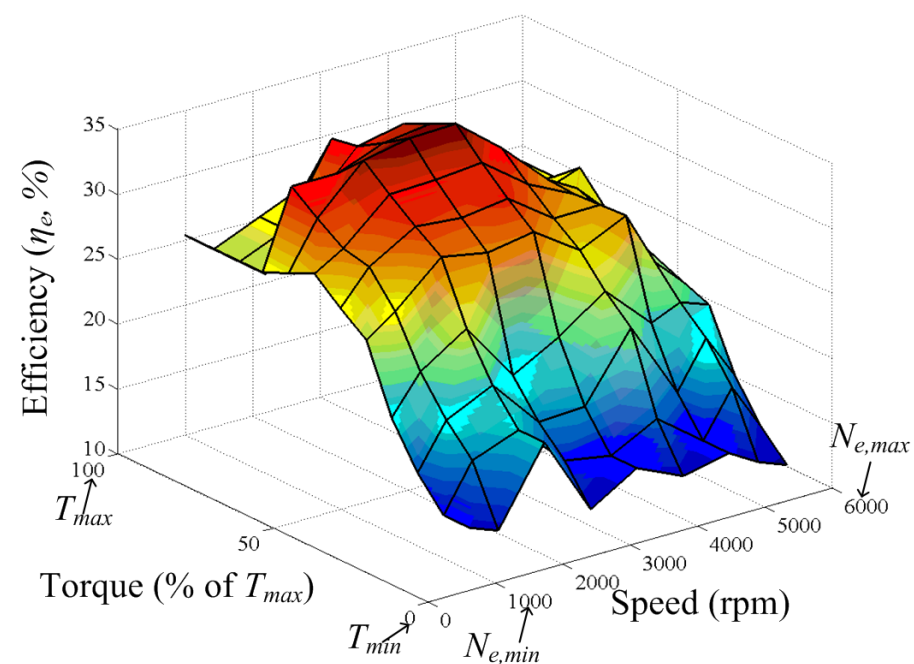

Fig. 2. ICE performance map - showing potential for relationship among the efficiency, brake torque and speed of the 1.0 L Geo ICE.

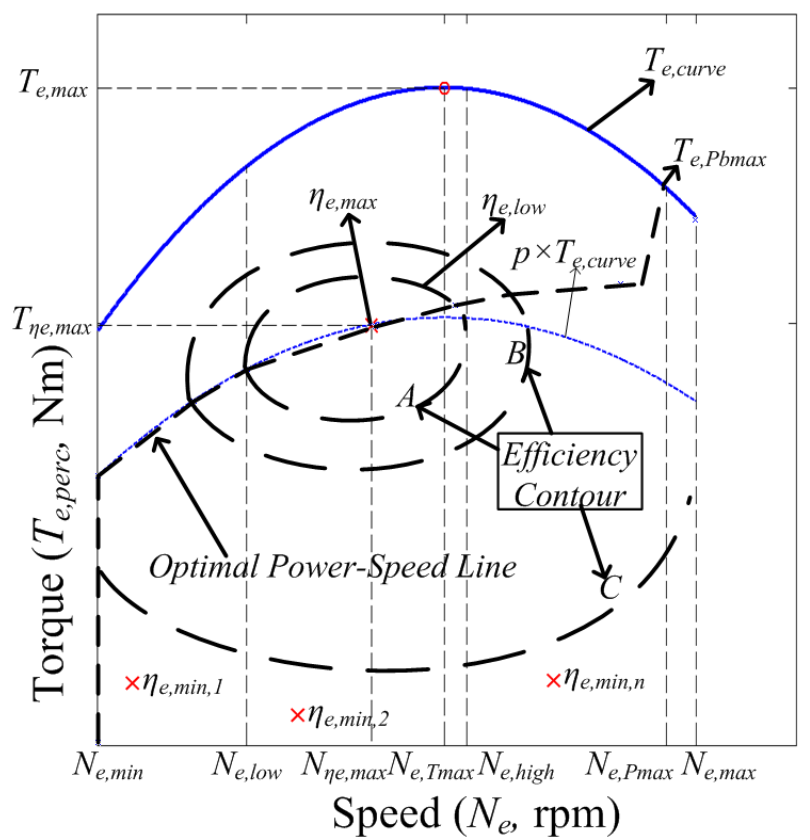

Fig. 3. ICE efficiency with respect to torque and speed - Example torque-speed curve and associated parameters defined by equations (1) to (8)

Then knowing that the rated power-speed point is the maximum achievable power occurring on the bmep characteristic at WOT $\left(N_{e, P \max }, P_{b \max }\right)$;

$$
T_{e, P b \max }=\frac{30 P_{b \max }}{\pi N_{e P \max }}
$$

Substituting (4) into (1), realises;

$$
P_{b \max }=\frac{2 \pi}{60} \times\left(a N_{e, P \max }^{3}+2 b N_{e, P \max }^{2}+d N_{e, P \max }\right)
$$

Rearranging and equating (3) and (5) with respect to $d$, with the substitution of (2) rearranged for $b$, an equation for $a$ is realised. Once $a$ is determined, it can be substituted into (2) to determine $b$. Then $a$ and $b$ can be substituted into (3) or (5) to determine $d$. With $a, b$ and $d$ defined, the considered torquespeed characteristic of the ICE can be estimated from known name plate information or torque-speed data points of the ICE to be modelled. 


\section{B. ICE Efficiency Model}

Here a model for the efficiency of operation for the ICE of a vehicle has been developed based on the use of the performance map identified in Figure 2. From Figure 3, an example of the efficiency contours for the ICE (Figure 2) are identified on the torque speed curve, with A having the highest efficiency values, followed by $\mathrm{B}$ and then $\mathrm{C}$. The ideal operation of any ICE is to achieve the highest efficiency such as that indicated by $\eta_{e, \max }$ or occurring within the region of $\mathrm{A}$ [21]. It is also advantageous to determine the optimal powerspeed line of Figure 4 which allows the controller to meet the variable speed requirements in addition to the PBS. Using the minimum power $\left(T_{e}=0 \mathrm{Nm}\right)$ at idle speed $\left(N_{e, \min }\right)$ and maximum power $\left(P_{\text {bmax }}\right)$ in addition to the maximum efficiency point of the ICE $\left(T_{\eta e, \max }, N_{\eta e, \max }\right)$ the optimal powerspeed line is estimated. An example of the optimal power speed line is shown in Figure 3 which is determined using the same information as for the proposed high efficiency map.

Figure 4 identifies an example of the efficiency contours in a three dimensional projection with respect to percentage of maximum brake torque ( $T_{e, \text { curve }}$ at WOT) and operating speed $\left(N_{e}\right)$. Figure 4 directly correlates with points identified in Figure 3 and depicts the end result expected from the proposed model having modelled data similar to that shown in Figure 2.

The purpose of modelling such data allows for the instantaneous prediction of any torque-speed point in the sample space considered for the ICE operation. Through the use of parabolic estimation the data of Figure 2 can be defined using data measured from up to eight ICE operating conditions. These eight operating conditions must correspond to the maximum power $\left(P_{b \max }, N_{e, \text { Pbmax }}\right)$, maximum torque $\left(T_{e, \max }, N_{e, \text { Tmax }}\right)$, and maximum $\left(\eta_{e, \max }\right)$ and minimum $\left(\eta_{e, \min }\right)$ efficiencies of the ICE in order to predict the efficiency of operation within acceptable error limits. The minimum efficiency of the ICE may need to be an average of multiple efficiency measurements taken at low torque and varying speed due to inaccuracy of measurement or volatility of operating efficiency, hence the three points shown in Figure 3, $\eta_{e, \min , 1}, \eta_{e, \min , 2}$ and $\eta_{e, \min , n}$.

The requirement for the estimation of the efficiency map is that the shape of the data is modelled for the torque and speed variations. Equations can be derived from the previously identified data points that define the performance map within acceptable error limits. From Figure 4;

$$
\eta_{e}=\eta_{T} \eta_{N}
$$

where $\eta_{e}$ is the efficiency of the ICE modelled and $\eta_{T}$ and $\eta_{N}$ represent the components that map the efficiency with respect to the torque and speed. It follows that;

$$
\eta_{T}=\xi T_{e, p e r c}^{2}+\chi T_{e, p e r c}+\psi
$$

For $p>0.5$

$$
\begin{aligned}
\xi & =\frac{\eta_{e, \min }-1}{p T_{e, \text { curve }}^{2}} \\
\chi & =-2 \xi p T_{e, \text { curve }} \\
\psi & =\eta_{e, \min }
\end{aligned}
$$

And for $p \leq 0.5$

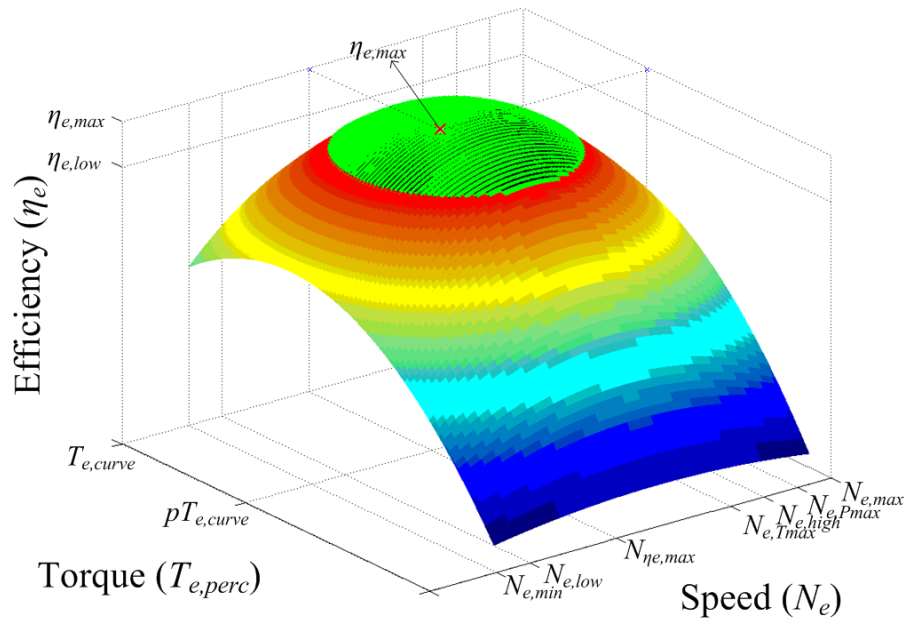

Fig. 4. Example ICE efficiency model and control limitations placed on the ICE for efficient operation. The high efficiency region is highlighted by the shaded cap of the 3D model.

$$
\begin{aligned}
\xi & =\frac{\eta_{T, \max }-\eta_{e, \max }}{T_{e, \text { curve }}^{2}\left(1-2 p+2 p^{2}\right)} \\
\chi & =-2 \xi p T_{e, \text { curve }} \\
\psi & =\eta_{e, \max }-\xi T_{e, \text { curve }}^{2}-b T_{e, \text { curve }}
\end{aligned}
$$

The need for the piecewise definition of the coefficients in (7), relates to the selection of $p$ as the percentage maximum brake torque at which the ICE operates at maximum efficiency $\left(\eta_{e, \max }\right) \cdot p$ acts as a reference for the parabolic shape of the performance map as the torque varies according to $T_{e, \text { perc }}$ (identified in Figure 4). If $p$ is less than 0.5 the efficiency of operation is higher for low torques and thus the model needs to account for this by referencing the lower efficiency that (in this case) occurs at $T_{\max }$ or $T_{e, \text { curve. }}$ If the model did not account for this variation the efficiency plot would become skewed and for $p \leq 0.5$ the proposed model would not work. Equation (7) is therefore able to predict the efficiency of the ICE for constant speed and varying torque up to the torque at WOT, in this case referred to as $T_{e, \text { curve }}$. Next varying speed must be considered to complete the efficiency map model.

$$
\begin{aligned}
& \eta_{N}=\delta N_{e}^{2}+\theta N_{e}+\varphi \\
& \delta=\frac{\eta_{N e, \text { max }}-\eta_{e, \text { max }}}{N_{e, \text { max }}^{2}-2 N_{\eta f, \text { max }} N_{e, \text { max }}+N_{\eta f, \text { max }}^{2}} \\
& \theta=-2 \delta N_{\eta f, \text { max }} \\
& \varphi=\eta_{N e, \text { max }}-\delta N_{e, \text { max }}^{2}-\theta N_{e, \text { max }}
\end{aligned}
$$

The use of (7) and (14) when substituted into equation (6) relies on the torque and speed points correlating to a single efficiency value. This means that $N_{e}$ and $T_{e \text {,perc }}$ represent an arbitrary operating condition in the performance map of the ICE to be modelled.

\section{RESUltS}

\section{A. ICE Efficiency Model Accuracy}

The efficiency maps for each ICE were predicted using the specifications taken from ADVISOR [23] as listed in Table I. 
TABLE I

SPECIFICATIONS OF ICE WITH KNOWN CHARACTERISTICS

\begin{tabular}{|c|c|c|c|c|c|c|c|c|}
\hline Symbol & Quantity & $\begin{array}{l}1.0 \mathrm{~L} \mathrm{Geo} \\
\text { (i) }\end{array}$ & $\begin{array}{l}\text { 1.9 L Saturn } \\
\text { SOHC } \\
\text { (ii) }\end{array}$ & $\begin{array}{l}1.9 \text { L Saturn } \\
\text { DOHC } \\
\text { (iii) }\end{array}$ & $\begin{array}{l}1.9 \text { L Volkswagen } \\
\text { (iv) }\end{array}$ & $\begin{array}{c}3.0 \mathrm{~L} \\
\text { Dodge } \\
(\mathrm{v})\end{array}$ & $\begin{array}{c}8.1 \mathrm{~L} \\
\text { John } \\
\text { Deere } \\
\text { (vi) }\end{array}$ & Unit \\
\hline$T_{e, \max }$ & Maximum torque & 81 & 145 & 165 & 182 & 217 & 1085 & $\mathrm{Nm}$ \\
\hline$N_{e, \max }$ & Maximum speed & 5700 & 5500 & 6000 & 4500 & 4875 & 2200 & $\mathrm{rpm}$ \\
\hline$N_{e, \operatorname{Tmax}}$ & Speed at maximum torque & 3477 & 2000 & 3500 & 2250 & 4143 & 1400 & $\mathrm{rpm}$ \\
\hline$\eta_{e, \max }$ & $\begin{array}{l}\text { Percentage maximum fuel } \\
\text { consumption efficiency }\end{array}$ & 0.341 & 0.345 & 0.345 & 0.394 & 0.293 & 0.395 & - \\
\hline$\eta_{p}$ & $\begin{array}{l}\text { Efficiency corresponding to } \\
\mathrm{pT}_{\mathrm{e}, \text { curve }} \text { at } \mathrm{N}_{\mathrm{e}, \max }\end{array}$ & 0.243 & 0.294 & 0.283 & 0.352 & 0.175 & 0.375 & - \\
\hline$\eta_{e, \min }$ & $\begin{array}{l}\text { Percentage minimum fuel } \\
\text { consumption efficiency } \\
\text { Percentage of Maximum }\end{array}$ & 0.100 & 0.000 & 0.100 & 0.000 & 0.100 & 0.300 & - \\
\hline
\end{tabular}

TABLE II

CALCUlating THE ACCURACY OF THE ICE EFFICIENCY MODEL FOR RESPECTIVE ICE'S

\begin{tabular}{|c|c|c|c|c|c|c|c|}
\hline Symbol & Quantity & $\begin{array}{l}1.0 \mathrm{~L} \mathrm{Geo} \\
\text { (i) }\end{array}$ & $\begin{array}{l}1.9 \text { L Saturn } \\
\text { SOHC } \\
\text { (ii) }\end{array}$ & $\begin{array}{c}1.9 \text { L Saturn } \\
\text { DOHC } \\
\text { (iii) }\end{array}$ & $\begin{array}{l}1.9 \text { L Volkswagen } \\
\text { (iv) }\end{array}$ & $\begin{array}{l}\text { 3.0 L Dodge } \\
\text { (v) }\end{array}$ & $\begin{array}{c}8.1 \mathrm{~L} \mathrm{John} \\
\text { Deere } \\
\text { (vi) }\end{array}$ \\
\hline - & $\begin{array}{l}\text { High efficient region - } \\
\text { Percentage of torque-speed area }\end{array}$ & $16.67 \%$ & $18.18 \%$ & $36.36 \%$ & $37.50 \%$ & $18.52 \%$ & $25.93 \%$ \\
\hline$\eta_{e, \text { low }} / \eta_{e, \max }$ & $\begin{array}{l}\text { Low efficiency limit ratio w.r.t. } \\
\text { max efficiency }\end{array}$ & $81.76 \%$ & $78.85 \%$ & $80.00 \%$ & $81.20 \%$ & $80.22 \%$ & $94.43 \%$ \\
\hline
\end{tabular}

The predicted ICE efficiency maps are then compared for each operating condition (consisting of an efficiency, torque and speed value) that corresponds to the efficiency maps utilized in ADVISOR to determine the accuracy of the proposed model. In addition to the comparison against the performance maps, existing ICE performance models have been utilized to predict the efficiency of operation for the same data points and a comparison of errors has been made with the proposed model.

Firstly consider a comparison of Figure 2 and Figure 4 which display the discretely defined efficiency map and predicted efficiency map (calculated by the proposed efficiency model) respectively, of the $1.0 \mathrm{~L}$ Geo (Table I [24]). Both of these figures have noticeable differences between the known performance map (Figure 2) and the proposed model (Figure 4). The main observation to consider for this comparison is that the high efficiency region of the predicted performance map correlates with the high efficiency region of the known performance map (having the same $\left.\eta_{e, \max }\right)$. The shaded cap of Figure 4 being the high efficiency region for example has little error when compared against the cap (or high efficiency region of the ICE) of the original data (Figure 2).

The three existing ICE performance models identify polynomial relationships among the ICE operating conditions; namely fuel consumption rate, brake torque and speed of the ICE similar to the proposed model. The key difference is that each model represents a full data set without reference to specific operating conditions in the sample space, thus requiring a larger sample space of the ICE performance map. Existing model 1 is a polynomial response surface methodology (RSM) of degree 2 as featured in [25]. Existing model 2 is a polynomial RSM of degree 3 with the addition of sump oil temperature for modelling hot and cold operations [7]. If the oil temperature is assumed constant this model is also capable of modelling the ADVISOR performance maps considered in this paper. Existing model 3 is a rational polynomial of degree 3 , which is a simplified version of the Willian's line model commonly used in ICE fuel consumption rate estimation [20].

In order to determine an RSM a number of operating conditions of a given ICE are required. An operating condition is the measurement of fuel consumption rate, brake torque and speed of the ICE at any given time, the variations in torque and speed result with such performance maps as shown in Figure 2. Each ICE considered here has at least 54 operating conditions which have been utilized in modelling depending on the total number available in ADVISOR, highlighting the large sample spaces required. Each ICE in Table I have been given a number for reference in Figure 5.

For the concern of efficiency of operation for the six ICEs selected, it is assumed that operation would be restricted to some high efficiency region when employing the proposed model. Referring to Figure 4 the shaded cap of the performance map is considered as the high efficiency region, which also corresponds to region A identified in Figure 3.This extends from the use of the performance map in the previous study completed by the authors as featured in [21]. This high efficiency region identifies a user defined lower limit in the ICE efficiency of operation $\left(\eta_{e, \text { low }}\right)$.

For the calculation of the accuracy of the proposed model and existing models, a low efficiency limit ratio $\left(\eta_{e, \text { low }} / \eta_{e, \text { max }}\right)$ with respect to the maximum efficiency capable by the ICE of $80 \%$ has been selected as identified in Table II. In addition the high efficiency region as a percentage of the total area of the torque and speed operating conditions has been identified to 
show that the area of the performance map being modelled is sufficient and has not been reduced for improved correlation. The high efficiency region is the percentage ratio of the number of operating conditions tested against the total number of operating conditions available from the ADVISOR performance maps. An example of this percentage ratio is the division of data points contained within the cap of the efficiency plot in Figure 4 by the total number of data points in the entire efficiency plot. This means that ICE (i) to ICE (vi) have high efficiency regions that make up at least $16.67 \%$ of the possible torque-speed operating conditions available. In the case of ICE (vi) with a ratio $\left(\eta_{e, \text { low }} / \eta_{e, \max }\right)$ of $94.43 \%$ this is due to the high average efficiency of the ICE for the entire plot. The high efficiency region's size for ICE (vi) has been selected according to the size of other ICEs tested which range between $16.67 \%$ to $37.50 \%$. $25.93 \%$ is therefore an acceptable sample space based on the size of other ICEs high efficiency regions.

For each operating point significant to the predicted performance map (Figure 4), the mean absolute percentage error (MAPE featured in [3]) has been determined as presented in Figure 5. This comparison indicates that all three existing models for ICE efficiency of operation exhibit some variation in accuracy for modelling the same high efficiency region - highlighted in Figure 4 by the shaded cap of the three dimensional plot. The average errors (AVG) are the same for all six ICEs tested which indicates that the proposed method for determining the ICE operating efficiency will work as well as the existing methods. Therefore time consumed in acquiring the necessary measured data of ICE performance may be avoided if the proposed model is utilised. The ability of the proposed model to achieve this accuracy is due to the consideration of eight significant data points that define the ICE operation.

Relative to the study previously completed by the authors [21] the defined efficiency model is capable of restricting ICE operation to some high efficiency region. The controller will establish an optimal value of $\eta_{\text {ellow }}$ as required to reduce the fuel consumption for different drive scenarios. This leads to the integration of the proposed efficiency model into a control system for demonstrating the effect it may have on the fuel consumption of PHEV and HEV.

\section{B. Integration of Proposed Model in a Plug-in Hybrid Electric Vehicle}

Utilising the same control strategy as defined in [21], the selection of the of the high efficiency region is determined by the efficiency model defined in this paper. The previously developed Toyota Prius model as outlined in [21] is utilised for simulation and comparison of using the proposed ICE efficiency model. For ICE operation a requested operating torque $\left(T_{e}{ }^{\prime}\right)$ and speed $\left(N_{e}\right)$ must meet the following constraint;

$$
\eta_{e}\left(T_{e}, N_{e}\right) \geq \eta_{e, l o w}
$$

Rules for operating conditions that lie outside this defined high efficiency region for ICE operation are defined in [21]. The ICE utilised for the simulation is a scaled version (according to the power rating) of the $1.9 \mathrm{~L}$ Saturn DOHC

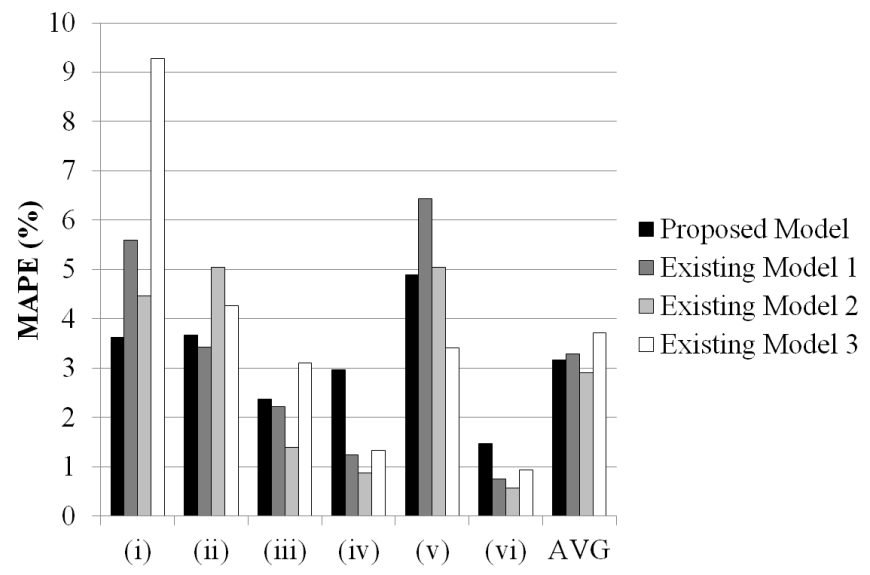

Fig. 5. Mean absolute percentage error (MAPE)- Comparison of the six ICEs modelled for the proposed model and the three selected existing models.

which is ICE (iii) from the previous analysis of the six ICE tested (Table I).

From Table III, the simulation results listed under the original model represents the existing controller for the Toyota Prius 2010 and is used as the bench mark. An optimal high efficiency region is found by varying $\eta_{e \text {, low }}$ for three drive cycles. Firstly, using the performance map an $\eta_{e, \text { low }}=28 \%$ is found to achieve the best fuel consumption then using this as a starting point the $\eta_{e, \text { low }}$ for the proposed ICE efficiency model is determined at $\eta_{e, l o w}=11 \%$. A similar method for determining $\eta_{e, \text { low }}$ may be required during simulations before implementation to an experimental setup.

The urban dynamo driving schedule (UDDS) and new European drive cycle (NEDC) are representative of city drive cycles and the highway fuel economy test (HWFET) is representative of highway driving. Table III indicates that the use of the proposed model is performing with errors similar to that calculated in Figure 5. From Figure 5 the expected errors are up to $4 \%$ on average while the difference between using the proposed model and the performance map is found to be up to $5.5 \%$ with the city driving cycles having some improvement in comparison to the original vehicle model. Highway driving improvement is limited which may be due to the high average speed of the vehicle and therefore larger average power required to maintain the vehicle speed. Any restrictions place on the ICE may lead to increased fuel consumption during highway driving only [21]. The results of Table III demonstrate that for an undefined ICE performance map it is possible to utilise the proposed efficiency model to achieve the high efficiency control of the ICE in PHEV and HEV.

\section{CONCLUSIONS}

This paper proposed an alternative ICE efficiency model that can be utilized in designing controllers to minimize fuel consumption and associated GHG emissions. The proposed model predicts a high efficiency region for operation of ICEs using torque and speed. The calculation and therefore predictions made by the proposed model utilise a low number of operating conditions which from a research point of view mitigates the need for extensive experimental work to identify the performance map of an ICE. The accuracy of the proposed model applied to six known ICE performance maps has been 
TABLE III

EFFECT OF THE ICE EFFICIENCY MODEL ON FUEL CONSUMPTION IN AN EXAMPLE TEST BENCH

\begin{tabular}{|c|c|c|c|c|}
\hline $\begin{array}{l}\text { Drive } \\
\text { Cycle }\end{array}$ & $\begin{array}{l}\text { Component } \\
\text { Parameter }\end{array}$ & $\begin{array}{l}\text { Original } \\
\text { Model }\end{array}$ & $\begin{array}{c}\text { High } \\
\text { Efficiency } \\
\text { Control with } \\
\text { Performance } \\
\text { Map }\end{array}$ & $\begin{array}{c}\text { High } \\
\text { Efficiency } \\
\text { Control } \\
\text { with } \\
\text { Proposed } \\
\text { Model }\end{array}$ \\
\hline \multirow{6}{*}{ UDDS } & ESS Initial SOC (\%) & 60 & 60 & 60 \\
\hline & ESS Final SOC (\%) & 60.86 & 57.85 & 51.74 \\
\hline & $\begin{array}{l}\text { Overall Efficiency } \\
(\%)\end{array}$ & 10.31 & 10.73 & 10.48 \\
\hline & $\begin{array}{l}\text { Fuel Consumption } \\
(\mathrm{L} / 100 \mathrm{~km})\end{array}$ & 3.22 & 3.05 & 3.04 \\
\hline & FC Improvement (\%) & - & 5.28 & 5.59 \\
\hline & $\begin{array}{c}\text { Percentage } \\
\text { Difference (\%) } \\
\end{array}$ & - & - & 0.33 \\
\hline \multirow{6}{*}{ HWFET } & ESS Initial SOC (\%) & 65 & 65 & 65 \\
\hline & ESS Final SOC (\%) & 68.26 & 66.40 & 67.67 \\
\hline & $\begin{array}{c}\text { Overall Efficiency } \\
(\%)\end{array}$ & 18.84 & 19.31 & 18.94 \\
\hline & $\begin{array}{l}\text { Fuel Consumption } \\
(\mathrm{L} / 100 \mathrm{~km})\end{array}$ & 3.29 & 3.17 & 3.33 \\
\hline & FC Improvement (\%) & - & 3.65 & -1.22 \\
\hline & $\begin{array}{c}\text { Percentage } \\
\text { Difference (\%) }\end{array}$ & - & - & -5.05 \\
\hline \multirow{5}{*}{ NEDC } & $\begin{array}{l}\text { ESS Initial SOC (\%) } \\
\text { ESS Final SOC (\%) }\end{array}$ & $\begin{array}{c}60 \\
63.56\end{array}$ & $\begin{array}{c}60 \\
63.21\end{array}$ & $\begin{array}{c}60 \\
64.80\end{array}$ \\
\hline & $\begin{array}{c}\text { Overall Efficiency } \\
(\%)\end{array}$ & 13.69 & 14.71 & 14.05 \\
\hline & $\begin{array}{l}\text { Fuel Consumption } \\
(\mathrm{L} / 100 \mathrm{~km})\end{array}$ & 3.52 & 3.27 & 3.45 \\
\hline & FC Improvement (\%) & - & 7.10 & 1.99 \\
\hline & $\begin{array}{c}\text { Percentage } \\
\text { Difference }(\%)\end{array}$ & - & - & -5.50 \\
\hline
\end{tabular}

evaluated having significant correlation with less than $4 \%$ error on average for the high efficiency region. The authors envisage that with each specific application of energy management, differing $\eta_{e, \text { low }}$ values for optimal performance will be required. Future work for the proposed model relates to high efficiency control of ICEs in hybrid power systems in utility backup and off-grid applications. This potential for future work is realised through the demonstrated use of the proposed model in this paper since it is possible to determine ICE operating conditions that maximize the useful energy resulting from fossil fuel consumed.

\section{REFERENCES}

[1] O. Chiavola, "Integrated modelling of internal combustion engine intake and exhaust systems," Proc. Inst. Mech. Eng. A J. Power Energy, vol. 215, pp. 495-506, 2001.

[2] T. Huajin, W. Larry, D. Zhao Yang, \& Y. Rui, "Adaptive and Learning Control for SI Engine Model With Uncertainties," Mechatronics, IEEE/ASME Transactions on, vol. 14, pp. 93-104, 2009.

[3] N. Daiheng, \& D. Henclewood, "Simple Engine Models for VII-Enabled In-Vehicle Applications," Vehicular Technology, IEEE Transactions on, vol. 57, pp. 2695-2702, 2008.

[4] C. Bo-Chiuan, W. Yuh-Yih, W. Yi-Lin, \& L. Chan-Chiao, "Adaptive Power Split Control for a Hybrid Electric Scooter," Vehicular Technology, IEEE Transactions on, vol. 60, pp. 1430-1437, 2011.

[5] T. H. Bradley, \& A. A. Frank, "Design, demonstrations and sustainability impact assessments for plug-in hybrid electric vehicles," Renewable and Sustainable Energy Reviews, vol. 13, pp. 115-128, 2009.

[6] J. B. Heywood, Internal Combustion Engine Fundamentals. New York: McGraw-Hill, 1988.
[7] F. Jehlik, "Methodology and analysis of determining plug-In hybrid engine thermal state and resulting efficiency," in Advanced Hybrid Vehicle Powertrains, World Congress, SAE, Detroit, MI, Paper 2009-011308, 2009.

[8] S. Barsali, C. Miulli, and A. Possenti, "A control strategy to minimize fuel consumption of series hybrid electric vehicles," Energy Conversion, IEEE Transactions on, vol. 19, pp. 187-195, 2004.

[9] S. Delprat, J. Lauber, T. M. Guerra, \& J. Rimaux, "Control of a parallel hybrid powertrain: optimal control," Vehicular Technology, IEEE Transactions on, vol. 53, pp. 872-881, 2004.

[10]K. Jeongmin, K. Talchol, M. Byungsoon, H. Sungho, \& K. Hyunsoo, "Mode Control Strategy for a Two-Mode Hybrid Electric Vehicle Using Electrically Variable Transmission (EVT) and Fixed-Gear Mode," Vehicular Technology, IEEE Transactions on, vol. 60, pp. 793-803, 2011.

[11]D. Karbowski, S. Pagerit, J. Kwon, A. Rousseau, \& K.-F. Frieherr von Pechmann, "“Fair" Comparison of Powertrain Configurations for Plug-In Hybrid Operation Using Global Optimization," in Advanced Hybrid Vehicle Powertrains, World Congress, SAE, Detroit, MI, Paper 2009-011334, 2009.

[12]F. Syed, S. Nallapa, A. Dobryden, C. Grand, R. McGee, et al., "Design and Analysis of an Adaptive Real-Time Advisory System for Improving Real World Fuel Economy in a Hybrid Electric Vehicle," in Advanced Hybrid Vehicle Powertrains, World Congress, SAE, Detroit, MI, Paper 2010-01-0835, 2010.

[13]S. G. Wirasingha, \& A. Emadi, "Classification and Review of Control Strategies for Plug-In Hybrid Electric Vehicles," Vehicular Technology, IEEE Transactions on, vol. 60, pp. 111-122, 2011.

[14]M. Ehsani, Y. Gao, \& A. Emadi, Modern electric, hybrid electric, and fuel cell vehicles : fundamentals, theory, and design, 2 nd ed. Boca Raton: CRC Press, 2010.

[15]T. Hofman, S. Ebbesen, and L. Guzzella, "Topology Optimization for Hybrid Electric Vehicles With Automated Transmissions," Vehicular Technology, IEEE Transactions on, vol. 61, pp. 2442-2451, 2012.

[16]Q. Wang, W. Liang, M. Kuang, \& R. McGee, "Vehicle System Controls for a Series Hybrid Powertrain," in Advanced Hybrid Vehicle Powertrains, World Congress, SAE, Detroit, MI, Paper 2011-01-0860, 2011.

[17]W. Lianghong, W. Yaonan, Y. Xiaofang, \& C. Zhenlong, "Multiobjective Optimization of HEV Fuel Economy and Emissions Using the SelfAdaptive Differential Evolution Algorithm," Vehicular Technology, IEEE Transactions on, vol. 60, pp. 2458-2470, 2011.

[18]N. Kim, \& A. Rousseau "Comparison between Rule-Based and Instantaneous Optimization for a Single-Mode, Power-Split HEV," in Advanced Hybrid Vehicle Powertrains, World Congress, SAE, Detroit, MI, Paper 2011-01-0873, 2011.

[19]M. Neve, G. De Nicolao, G. Prodi, \& C. Siviero, "Estimation of Engine Maps: A Regularized Basis-Function Networks Approach," Control Systems Technology, IEEE Transactions on, vol. 17, pp. 716-722, 2009.

[20]D. Rotenberg, A. Vahidi, \& I. Kolmanovsky, "Ultracapacitor Assisted Powertrains: Modeling, Control, Sizing, and the Impact on Fuel Economy," Control Systems Technology, IEEE Transactions on, vol. 19, pp. 576-589, 2011.

[21]S. Overington and S. Rajakaruna, "High Efficiency Control of Internal Combustion Engines in Blended Charge Depletion/Charge Sustenance Strategies for Plug-in Hybrid Electric Vehicles," Vehicular Technology, IEEE Transactions on, vol. PP, pp. 1-1, 2014.

[22]I. Aharon and A. Kuperman, "Topological Overview of Powertrains for Battery-Powered Vehicles With Range Extenders," Power Electronics, IEEE Transactions on, vol. 26, pp. 868-876, 2011.

[23]K. B. Wipke, M. R. Cuddy, \& S. D. Burch, "ADVISOR 2.1: UserFriendly Advanced Powertrain Simulation Using A Combined Backward/Forward Approach," IEEE Trans. on Vehicular Technology, vol. 48, pp. 1751-1761, Nov. 1999.

[24]T. Markel, "ADVISOR Data file: FC_SI41_emis.M," ed. National Renewable Energy Laboratory, Golden, CŌ: NREL, 1998.

[25]A. A. Golverk, "Mathematical calculation of the performance map of internal combustion engine," in International Congress \& Exposition, SAE, Detroit, MI, Paper 920683, 1992. 